\title{
Are cognitive impairments associated with sensitivity to stress in schizophrenia? An experience sampling study.
}

Citation for published version (APA):

Germeys, I. Y. R., Krabbendam, A. C., Jolles, J., Delespaul, P. A. E. G., \& van Os, J. J. (2002). Are cognitive impairments associated with sensitivity to stress in schizophrenia? An experience sampling study. American Journal of Psychiatry, 159(3), 443-9. https://doi.org/10.1176/appi.ajp.159.3.443

Document status and date:

Published: 01/01/2002

DOI:

10.1176/appi.ajp.159.3.443

Document Version:

Publisher's PDF, also known as Version of record

\section{Please check the document version of this publication:}

- A submitted manuscript is the version of the article upon submission and before peer-review. There can be important differences between the submitted version and the official published version of record.

People interested in the research are advised to contact the author for the final version of the publication, or visit the DOI to the publisher's website.

- The final author version and the galley proof are versions of the publication after peer review.

- The final published version features the final layout of the paper including the volume, issue and page numbers.

Link to publication

\footnotetext{
General rights rights.

- You may freely distribute the URL identifying the publication in the public portal. please follow below link for the End User Agreement:

www.umlib.nl/taverne-license

Take down policy

If you believe that this document breaches copyright please contact us at:

repository@maastrichtuniversity.nl

providing details and we will investigate your claim.
}

Copyright and moral rights for the publications made accessible in the public portal are retained by the authors and/or other copyright owners and it is a condition of accessing publications that users recognise and abide by the legal requirements associated with these

- Users may download and print one copy of any publication from the public portal for the purpose of private study or research.

- You may not further distribute the material or use it for any profit-making activity or commercial gain

If the publication is distributed under the terms of Article $25 \mathrm{fa}$ of the Dutch Copyright Act, indicated by the "Taverne" license above, 


\section{Are Cognitive Impairments Associated With Sensitivity to Stress in Schizophrenia? An Experience Sampling Study}

\author{
Inez Myin-Germeys, Ph.D. \\ Lydia Krabbendam, Ph.D. \\ Jelle Jolles, Ph.D. \\ Philippe A. Delespaul, Ph.D. \\ Jim van Os, M.D., Ph.D.
}

\begin{abstract}
Objective: Patients with a diagnosis of schizophrenia display cognitive impairments and abnormal sensitivity to stress. However, little is known about the relationship between these two endophenotypes.
\end{abstract}

Method: Neuropsychological tests were administered to 42 patients with schizophrenia or other psychosis to assess cognitive functioning, and the experience sampling method (a structured diary technique assessing current context and mood in daily life) was used to assess 1) appraised subjective stress related to daily events and activities and 2) emotional reaction to these daily life stressors.

Results: Multilevel random regression analyses showed that in some instances, cognitive functioning did not alter emo- tional reaction to stress. In other instances, an inverse relationship was found, indicating that a better performance on neuropsychological tests was related to greater emotional reaction to stress.

Conclusions: The results indicate that emotional reaction to stress in the daily lives of patients with schizophrenia may not be a consequence of cognitive impairments and that the two mechanisms may act through different pathways. Such pathways may be related to the extremes of clinical outcome that have been observed in schizophrenia: an episodic, reactive, good outcome and a more chronic form characterized by high levels of negative symptoms and cognitive impairments.
$\mathrm{T}_{\mathrm{n}}$ he focus in schizophrenia research has been extended from overt symptoms to more subtle impairments that might constitute the underlying vulnerability for the disorder. There has been a long-standing interest in cognitive impairments as the possible substrate of schizophrenia vulnerability (1-4). Schizophrenia has been called a neurocognitive disorder (5), the true phenotype of which may be "an impairment in the smooth coordination of mental processes" or "cognitive dysmetria" $(6,7)$. Neuropsychological impairments are not merely neutral indicators of an underlying vulnerability but appear to contribute causally to course and outcome. For example, cognitive impairments are associated with prognostically unfavorable negative symptoms (8, 9), and several studies have provided evidence that cognitive impairments independently predict functional outcome $(10,11)$.

The precise mechanisms by which the statistical association between cognitive impairment and functional outcome is mediated remain unknown. It is attractive to speculate, however, that part of the association between neuropsychological vulnerability and functional outcome can be interpreted in terms of another dominant paradigm in schizophrenia research: the stress vulnerability model. It has been reported that patients suffering from schizophrenia are sensitive to life events $(12,13)$, daily hassles $(14,15)$, and critical environments $(16,17)$, and patients report more subjective stress than comparison subjects when confronted with the same objective situation
(17). The most parsimonious explanation linking findings on neuropsychological impairment and sensitivity to stress is to conceive of schizophrenia as the clinical manifestation of an impairment in higher brain functions that are necessary for the successful adaptation to the stresses of adult life. Thus, abnormal sensitivity to stress would lie on the causal pathway between cognitive impairments and the psychosis outcome. If this were true, one would expect the level of neuropsychological impairments to affect reactivity to daily life stress in patients with schizophrenia. Alternatively, however, neuropsychological impairments and sensitivity to stress may constitute independent or even mutually exclusive mechanisms associated with different clinical manifestations, along the lines first proposed by Robins and Guze (18). Thus, sensitivity to stress may be associated with a more episodic type of illness and a predominance of positive symptoms, whereas neuropsychological impairments may be associated with a more chronic illness involving high levels of negative symptoms.

In the present study, we used the experience sampling method to investigate the possible association between cognitive impairments and sensitivity to emotional stress in patients with schizophrenia.

\section{Method}

\section{Subjects}

The initial study group consisted of 50 subjects with psychosis. The selection criterion was a lifetime occurrence of psychotic 
symptoms, according to the Research Diagnostic Criteria, in clear consciousness for at least 2 weeks. The inclusion criteria were 1) age 18 to 55 years, 2) sufficient command of the Dutch language, and 3) normal findings from a physical examination. The exclusion criteria were 1) endocrine, cardiovascular, or brain disease, 2) use of alcohol in excess of five standard units per day, 3) weekly use of illicit drugs, 4) history of head injury with loss of consciousness, and 5) need of inpatient care, intensive case management home care, or case management crisis intervention. Written informed consent conforming to the guidelines of the local ethics committee was obtained from all subjects. The patients were recruited through the inpatient and outpatient mental health facilities in Maastricht, the Netherlands, and through patient associations in the southern part of the Netherlands.

All subjects were extensively screened before entering the study. Structured interviews were conducted by a research assistant and a research psychologist (I.M.-G.). The Brief Psychiatric Rating Scale (19) (kappa=0.77) and the Positive and Negative Syndrome Scale (20) (kappa=0.70) were used to map psychiatric symptoms. Data from interviews and clinical records were used to complete the Operational Criteria Checklist for Psychotic Illness, which was fed to the OPCRIT computer program, yielding DSM-III-R diagnoses (21).

\section{Neuropsychological Assessments}

The neuropsychological assessment was directed at the following cognitive domains: episodic memory, semantic fluency, attentional span, and speed of complex information processing. The Auditory Verbal Learning Task (22, 23, pp. 438-445) was used to evaluate learning and retrieval of information in episodic memory. In five consecutive trials, a list of 15 words has to be memorized and reproduced. The measure used was the total number of words recalled over the five trials. The backward digit span from the Wechsler Adult Intelligence Scale-Revised (24) was used as a measure of attentional span (23, pp. 357-368). The relevant variable was the number of sequences that the subject could repeat correctly. As measures of speed of information processing, we used the Stroop Color-Word Test (25) and the Concept Shifting Test (26), which is a modified version of the Trail Making Test (27). For both tests, the measure used was the interference score, which is the difference between performance on the complex task and performance on the simple task. For the Stroop Color-Word Test, this means the time needed for the subject to name the print color while ignoring the word minus the time needed for reading the color names. For the Concept Shifting Test, the interference score is the time needed for the subject to switch between numbers and letters minus the number-only condition. Word fluency was used to evaluate strategy-driven retrieval from semantic memory. The subjects had to generate as many animal names as possible in 1 minute (23, pp. 546-548).

\section{Experience Sampling Method}

Emotional reaction to stressors in daily life was measured with the experience sampling method, a within-day self-assessment technique. Previous applications of the experience sampling method in schizophrenia (28-31) have demonstrated the feasibility, validity, and reliability of the method in this population. Each subject received a digital wristwatch and a set of self-assessment forms collated in a booklet for each day. Ten times a day on 6 consecutive days, the watch emitted a signal (beep) at unpredictable moments between 7:30 a.m. and 10:30 p.m. After every beep, the subject recorded his or her thoughts, current context (activity, persons present, location), appraisals of the current situation, and mood. All self-assessments were rated on 7-point Likert scales.

The procedure was explained to the subjects during an initial briefing session, and a practice form was completed to confirm that the subjects were able to understand the 7-point Likert scale format. The subjects were instructed to complete each report immediately after the beep, thus minimizing memory distortion, and to record the time at which they completed the form. During the actual sampling period, research staff called each subject twice to assess whether he or she was complying with the instructions. On the basis of the times the subjects indicated they completed the reports, all reports completed more than 15 minutes after the signal were excluded from the analysis. Previous research (28) has shown that reports completed after this interval are less reliable and consequently less valid. Subjects with fewer than 20 valid reports were excluded from the analyses.

\section{Assessment of Emotional Reaction to Stress}

Emotional reaction to stress has been conceptualized as mood reactivity to daily events and minor disturbances in daily life (15). Both the mood measures and the stress measures in this study were derived from the experience sampling reports.

Assessment of mood. The mood states reported after each beep were assessed with 10 mood-related adjectives rated on 7point Likert scales ( $1=$ not at all, $7=$ very). Factor analyses (principal component analysis with Harris-Kaiser rotation) on the raw within-subject scores identified two factors with eigenvalues greater than 1 that explained $41 \%$ of the total variance. Two factor-based scales with equal weights for each item were created. The items down, guilty, insecure, lonely, and anxious formed the negative affect scale (Cronbach's alpha $=0.79$ ). The items happy, cheerful, relaxed, and satisfied formed the positive affect scale (Cronbach's alpha $=0.89$ ). The item angry had low loadings on both factors and was excluded to enhance differentiation between the two factors.

Assessment of stress. Stress was conceptualized as subjective appraised stressfulness of distinctive events and minor disturbances that continually happen in the natural flow of daily life. These were classified as event-related stress and activity-related stress. To determine event-related stress, after each beep the subject was asked to report the most important event that had happened between the current and previous reports. This event was subsequently rated on a 7 -point bipolar Likert scale (-3=very unpleasant, $0=$ neutral, $3=$ very pleasant). The responses were recoded to allow high scores to reflect stress $(-3=$ very pleasant, $0=$ neutral, $3=$ very unpleasant).

To measure activity-related stress, after each beep the subject judged the current activity on three self-report items scored on 7 point Likert scales ( $1=$ not at all, $7=$ very). The three items were "I am not skilled to do this activity," "I would rather do something else," and "This activity requires effort," and together they formed the activity-related stress scale (Cronbach's alpha $=0.54$ ).

\section{Positive and Negative Syndrome Scale}

At the end of the period of experience sampling, all subjects were assessed with the Positive and Negative Syndrome Scale (20). This scale includes seven items assessing positive symptoms and seven items assessing negative symptoms, scored on a 7point scale ( $1=$ not present, $7=$ extremely). The seven items for positive symptoms constitute the positive symptom scale, and the seven items for negative symptoms constitute the negative symptom scale.

\section{Statistics}

To estimate the effect of cognitive impairments on emotional reaction to daily life stress, a multilevel linear regression model (32) was used. Multilevel or hierarchical linear modeling techniques are a variant of the more often used unilevel linear analyses and are ideally suited for the analysis of data from experience sampling, which consist of multiple observations in one person 
(i.e., at two levels, beep level and subject level) (33). The beta ( $\beta$ ) values are the fixed regression coefficients of the predictors in the multilevel model and can be interpreted in a manner identical to that for the estimate in the unilevel linear regression analyses. The data were analyzed with the SAS PROC MIXED module (SAS Technical Report P-229, 1992).

Multilevel linear regression analyses were conducted with negative affect and positive affect as the dependent variables. The scores on the neuropsychological tests, the ratings on the two stress measures, and their interactions (stress by neuropsychological score) were the independent variables, leading to the following model: $\operatorname{mood}=\beta 0+\beta 1$ stress $+\beta 2$ neuropsychological score $+\beta 3$ (stress $\times$ neuropsychological score) + residual. Analyses were conducted separately for each measure of stress combined with each neuropsychological measure. Expression of the neuropsychological test results was made directionally similar for these analyses, in that higher scores indicated poorer performance. The interaction term was of most interest in the present study as the main question concerned whether neuropsychological functioning modifies emotional reaction to daily life stress. Therefore, stratified analyses were conducted whenever there was evidence of significant interaction effects. To this end, the subjects were divided into three groups according to their tertile group level of functioning on each neuropsychological test: the worst-performance group (the approximately $33 \%$ of the subjects with the lowest scores on the test), the intermediate-performance group (the 33\% of the subjects whose scores on the test fell into the middle tertile), and the best-performance group (the $33 \%$ of the subjects with the highest scores on the test). For each of the neuropsychological tests, emotional reaction to daily life stress was analyzed in the three groups separately according to the following model: $\operatorname{mood}=\beta 0+\beta 1$ stress + residual.

Finally, the positive and negative symptom scales were included in the multilevel model assessing the relation between stress and neurocognitive functioning, as possible confounders of the associations between stress and neurocognitive functioning, on the one hand, and mood, on the other.

\section{Results}

\section{Subjects and Descriptive Statistics}

Of the 50 subjects who entered the study, two patients did not return the diary booklets and six subjects completed fewer than 20 valid reports and were therefore excluded from the analysis. The final study group thus consisted of 42 subjects. They completed an average of 45 valid reports $(\mathrm{SD}=10)$.

Sociodemographic and clinical characteristics of the patients are summarized in Table 1, and the mean scores on the independent and dependent variables are shown in Table 2.

\section{Predictors of Mood States}

The multilevel random regression analyses showed a significant main effect of the two stress measures $(\beta 1)$ and neither a large nor a significant effect of neuropsychological functioning ( $\beta 2$ ) on mood (results not shown). Significant interaction effects $(\beta 3)$ (Table 3 ) were found with word learning, the Concept Shifting Test interference score, word fluency, and digit span, indicating that the scores on these neuropsychological tests modified the moment-tomoment emotional reaction to daily life stress. No signifi-
TABLE 1. Demographic and Clinical Characteristics of 42 Patients With Schizophrenia or Other Psychosis in a Study of Sensitivity to Stress

\begin{tabular}{lrccc}
\hline Characteristic & N & Mean & SD & Range \\
\hline Age (years) & & 31.9 & 7.7 & $20-48$ \\
Gender & 22 & & & \\
$\quad$ Male & 20 & & & \\
$\quad$ Female & & & & \\
Marital status & 9 & & & \\
$\quad$ Married or living together & 2 & & & \\
$\quad$ Divorced & 31 & & & \\
$\quad$ Never married & & & & \\
$\quad$ Work situation & 10 & & & \\
$\quad$ Working & 28 & & & \\
$\quad$ Unable to work & 4 & & & \\
$\quad$ Doing protected work & & & & \\
Education & 10 & & & \\
$\quad$ Elementary school & 28 & & & \\
$\quad$ Secondary school & 4 & 38.0 & 9.8 & $24-73$ \\
$\quad$ Higher education & & 22.5 & 5.8 & $14-41$ \\
$\quad$ Total BPRS score & & & \\
Age at first psychotic episode (years) & & & \\
$\quad$ OPCRIT DSM-III-R diagnosis (lifetime) & & & & \\
$\quad$ Schizophrenia & 39 & & & \\
$\quad$ Schizoaffective disorder & 2 & & & \\
$\quad$ Atypical psychosis & 1 & & &
\end{tabular}

cant interaction effects were found with the Stroop ColorWord Test interference score.

Stratified analyses were conducted to further clarify the associations between stress and mood in relation to neuropsychological test scores (Figure 1). Overall, the group with the best performance on the neuropsychological tests showed a stronger emotional reaction to stress, with larger decreases in positive affect and larger increases in negative affect than both the group with intermediate performance and the group with the worst performance.

When the scores on the positive and negative symptom scales from the Positive and Negative Syndrome Scale were entered into the multivariate analyses, the pattern of interactions between the stress measures and the neuropsychological assessments did not differ. There was no significant main effect of the negative symptom score on mood, while negative affect slightly increased with increase in the positive symptom score $(B=0.05, \mathrm{p}<0.05)$ and positive affect slightly decreased $(B=-0.07, \mathrm{p}<0.05)$.

\section{Discussion}

\section{Neurocognition and Sensitivity to Stress}

The present study showed that, in some instances, cognitive functioning did not alter the moment-to-moment emotional reaction to stress. In other instances, an inverse relationship was found, indicating that a better performance on the neuropsychological tests was related to more sensitivity to daily life stress. The present results therefore suggest that moment-to-moment sensitivity to stress may not be a consequence of cognitive impairments and that these mechanisms may act on different pathways that may even be mutually exclusive to a degree. There is evidence that both cognitive impairments and abnormal 
TABLE 2. Ratings and Correlations of Neuropsychological Performance, Stress, Mood, and Positive and Negative Symptoms for 42 Patients With Schizophrenia or Other Psychosis ${ }^{a}$

\begin{tabular}{|c|c|c|c|c|c|c|c|c|}
\hline \multirow[b]{2}{*}{ Measure } & \multicolumn{3}{|c|}{ Score } & \multicolumn{5}{|c|}{ Correlation (r) } \\
\hline & Mean & SD & Range & Item 1 & Item 2 & Item 3 & Item 4 & Item 5 \\
\hline \multicolumn{9}{|l|}{ Neuropsychological measures } \\
\hline 1. Word learning (Auditory Verbal Learning Task) & 48.6 & 8.2 & 29 to 64 & 1.00 & & & & \\
\hline 2. Word fluency (number of animals named in 1 minute) & 21.7 & 7.0 & 8 to 37 & $0.31^{* * * *}$ & 1.00 & & & \\
\hline 3. Stroop Color-Word Test, interference & 51.1 & 19.1 & 23 to 96 & $0.18^{* * *}$ & $0.32^{* * * *}$ & 1.00 & & \\
\hline 4. Concept Shifting Test, interference & 12.7 & 10.4 & 0.4 to 56.2 & $0.26^{* * *}$ & $0.06^{*}$ & $0.41^{* * * *}$ & 1.00 & \\
\hline 5. WAIS-R backward digit span & 5.8 & 1.6 & 3 to 11 & $0.29 * * * *$ & $0.09 * * *$ & $0.07^{* *}$ & $0.31^{* * * *}$ & 1.00 \\
\hline \multicolumn{9}{|l|}{ Stress measures ${ }^{a-d}$} \\
\hline 1. Event-related stress & -1.2 & 0.9 & -3 to 3 & 1.00 & & & & \\
\hline 2. Activity-related stress & 2.5 & 0.7 & 1 to 7 & $0.17^{* * *}$ & 1.00 & & & \\
\hline \multicolumn{9}{|l|}{ Mood measures ${ }^{a, b, e}$} \\
\hline 1. Positive mood & 4.4 & 1.0 & 1 to 7 & 1.00 & & & & \\
\hline 2. Negative mood & 1.7 & 0.7 & 1 to 7 & $-0.43^{* * *}$ & 1.00 & & & \\
\hline \multicolumn{9}{|l|}{ Positive and Negative Syndrome Scale } \\
\hline 1. Positive symptoms & 11.3 & 4.8 & 7 to 25 & 1.00 & & & & \\
\hline 2. Negative symptoms & 11.3 & 6.0 & 7 to 34 & $-0.17^{* * * *}$ & 1.00 & & & \\
\hline
\end{tabular}

a By the experience sampling method, each patient made entries in a diary whenever signaled to do so by beeps from a digital wristwatch. After each beep the subject reported the most important event that had happened between the current and previous reports; these events were subsequently rated to measure event-related stress. The subject also rated the skill, enjoyment, and effort involved in his or her current activity; the mean rating was used as a measure of activity-related stress. Ratings of mood-related adjectives were averaged to provide a measure of negative mood and a measure of positive mood.

b For each subject, the correlation between the two stress measures and the correlation between the two mood levels was calculated over all reports (maximum, 60). Subsequently, each of these correlations was considered as an individual-level variable and corrected with a Fisher $\mathrm{z}$ transformation. One-sample two-tailed t tests (alpha $=0.05)$ were conducted to test whether the mean of these individual-level correlation coefficients significantly deviated from zero.

c For event-related stress, skewness $=0.86$ and kurtosis $=-0.15$. For activity-related stress, skewness $=0.88$ and kurtosis $=0.63$.

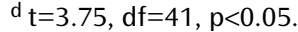

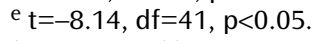

$* \mathrm{p}<0.05 . \quad * * \mathrm{p}<0.01 . \quad * * * \mathrm{p}<0.001$

TABLE 3. Multilevel Model Estimates of the Effect of Neuropsychological Performance on the Association Between Mood and Stress for 42 Patients With Schizophrenia or Other Psychosis ${ }^{\mathrm{a}}$

\begin{tabular}{|c|c|c|c|c|c|c|c|c|c|c|c|c|}
\hline \multirow[b]{3}{*}{ Neuropsychological Measure } & \multicolumn{6}{|c|}{ Positive Mood ${ }^{b}$} & \multicolumn{6}{|c|}{ Negative Mood $^{\text {b }}$} \\
\hline & \multicolumn{3}{|c|}{ Event-Related Stress } & \multicolumn{3}{|c|}{ Activity-Related Stress } & \multicolumn{3}{|c|}{ Event-Related Stress } & \multicolumn{3}{|c|}{ Activity-Related Stress } \\
\hline & B & SE & $\begin{array}{c}F(d f=1 \\
1676)\end{array}$ & B & SE & $\begin{array}{c}F(d f=1 \\
1782)\end{array}$ & B & SE & $\begin{array}{c}F(d f=1, \\
1676)\end{array}$ & B & SE & $\begin{array}{c}F(d f=1 \\
1782)\end{array}$ \\
\hline Word learning (Auditory & & & & & & & & & & & & \\
\hline Verbal Learning Test) & 0.007 & 0.002 & $16.81^{* * * *}$ & 0.014 & 0.002 & $32.41 * * *$ & -0.002 & 0.001 & $4.35^{*}$ & -0.010 & 0.002 & $28.26^{* * *}$ \\
\hline $\begin{array}{l}\text { Stroop Color-Word Test, } \\
\text { interference }\end{array}$ & 0.001 & 0.001 & 0.55 & 0.001 & 0.001 & 0.87 & 0.000 & 0.000 & 2.13 & 0.001 & 0.001 & 0.58 \\
\hline $\begin{array}{l}\text { Concept Shifting Test, } \\
\text { interference }\end{array}$ & -0.001 & 0.002 & 0.71 & 0.010 & 0.002 & $16.78^{* * *}$ & 0.000 & 0.001 & 0.01 & -0.008 & 0.002 & $16.48^{* * *}$ \\
\hline Word fluency & 0.003 & 0.002 & 2.24 & 0.004 & 0.003 & 1.61 & -0.004 & 0.001 & $9.75^{* *}$ & 0.001 & 0.002 & 0.13 \\
\hline WAIS-R backward digit span & -0.002 & 0.008 & 0.07 & -0.003 & 0.012 & 0.05 & -0.013 & 0.006 & $4.70^{*}$ & -0.025 & 0.009 & $6.93^{* * *}$ \\
\hline
\end{tabular}

${ }^{a}$ By the experience sampling method, each patient made entries in a diary whenever signaled to do so by beeps from a digital wristwatch. After each beep the subject reported the most important event that had happened between the current and previous reports; these events were subsequently rated to measure event-related stress. The subject also rated the skill, enjoyment, and effort involved in his or her current activity; the mean rating was used as a measure of activity-related stress. Ratings of mood-related adjectives were averaged to provide a measure of negative mood and a measure of positive mood.

${ }^{b}$ The numbers of beeps used in the regression analyses were 1,720 for the analyses with event-related stress and 1,826 for the analyses with activity-related stress.

${ }^{*} \mathrm{p}<0.05 . \quad * * \mathrm{p}<0.01 . \quad * * * \mathrm{p}<0.0001$.

sensitivity to stress are also present in the first-degree relatives of patients, albeit to a lesser degree $(15,34,35)$. This, in combination with the current findings, may indicate that the two vulnerabilities are transmitted independently, and it is attractive to speculate that they represent the underlying mechanism of the extensive clinical heterogeneity in schizophrenia that many have suggested can be reduced to two main forms: an episodic, reactive, goodoutcome form and a more chronic form characterized by high levels of negative symptoms and neurocognitive im- pairment $(18,36-39)$. More research is necessary to clarify the association between these endophenotypes and symptom levels.

The differences in the statistical associations of the different stress measures and neurocognitive tests with mood (some associations did not reach significance while others did) are in all likelihood related to the fact that a variety of different variables are used to map neuropsychological functioning, which are all correlated with each other to a degree but also represent independent do- 
FIGURE 1. Significant Interactions Between Neuropsychological Performance and Effects of Daily Events and Activities on Positive Mood and Negative Mood in 42 Patients With Schizophrenia or Other Psychosis ${ }^{a}$

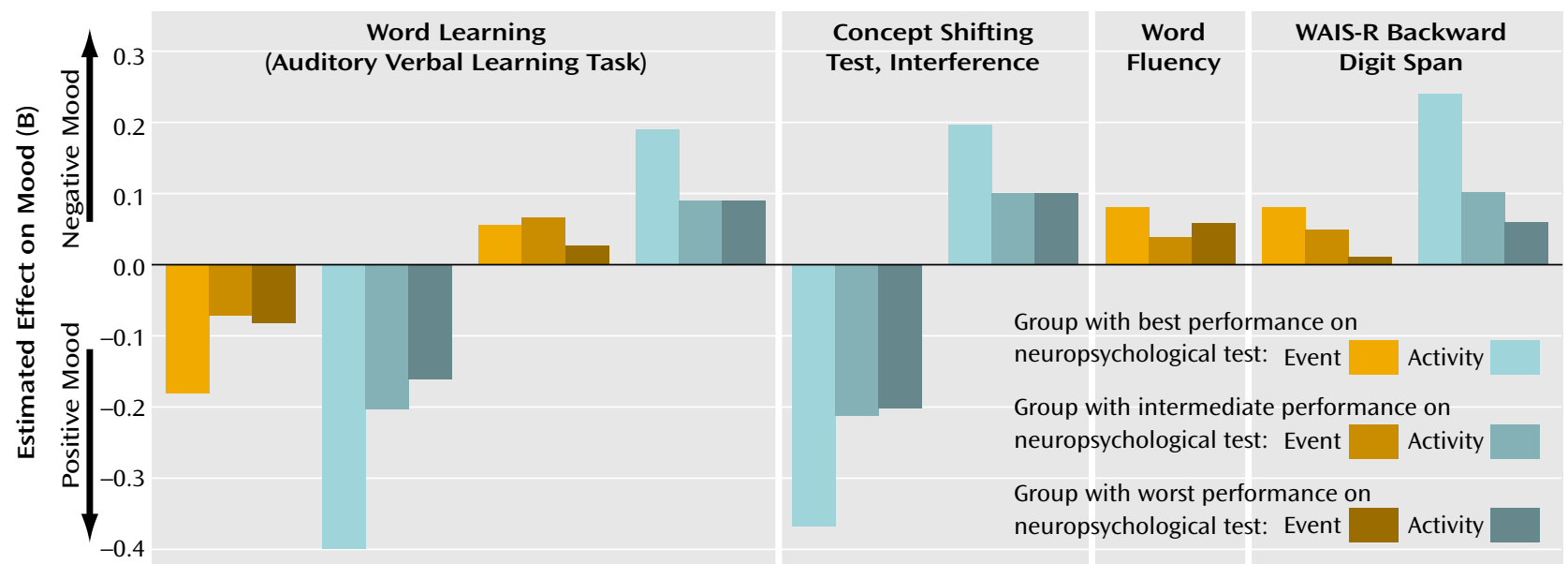

a By the experience sampling method, each patient made entries in a diary whenever signaled to do so by beeps from a digital wristwatch. After each beep the subject reported the most important event that had happened between the current and previous reports; these events were subsequently rated to measure event-related stress. The subject also rated the skill, enjoyment, and effort involved in his or her current activity; the mean rating was used as a measure of activity-related stress. Ratings of mood-related adjectives were averaged to provide a measure of negative mood and a measure of positive mood.

mains, with different sources of variability. Thus, some neurocognitive tests were more sensitive to differences in mood reactivity to certain stressful situations.

Alternative explanations for the reported results can be postulated. Sensitivity to stress is measured by means of self-report and, therefore, requires the capacity of introspection. First, neuropsychological deficits might impair the capacity to reflect on one's own inner mood states. However, this seems unlikely given that no main effects on mood were found for neuropsychological functioning. It has also been reported that cognitive impairments are related to negative symptoms such as flat affect, which might reduce emotional responsiveness (40). However, there is evidence that flat affect is more a dysfunction in expression of emotions than in experience of emotions $(30,41)$. Previous research with the experience sampling method (30) showed that patients who were blunted affectively reported the same intensity and fluctuation in positive and negative emotions as did patients without blunting. Second, a certain level of cognitive functioning might be necessary in order to experience the environment, for example stress, and report it. This hypothesis, however, again seems unlikely as subjective appraisals of stress were not associated with the neuropsychological test results. In comparisons of the cognitively best-performing group with the two other groups (intermediate and worst performance), no differences were found in mean, standard deviation, variance, and range of the subjective appraisal of both stress related to activities and stress related to events. Of course, the subjective appraisals of stress may be related to qualitatively different objective situations. For example, the patients with the best cognitive performance spent about $25 \%$ of their time in work-related activities, compared to only $6 \%$ in the two other groups. The latter, on the other hand, spent more time doing nothing ( $12 \%$ compared to $6 \%$ in the group with the best cognitive performance) and doing leisure activities (30\% versus $22 \%$ ). For the present analyses, however, the differences in objective situation do not matter, as the subjective appraisals of stress were used as the primary independent variable. Even if it were argued that work-related stress is different in nature from stress related to other activities, a post hoc exclusion of all work moments showed that this did not change the pattern of results. (In the reports made for all beeps, the estimated effects [B] of activity-related stress were 0.16 [SE $=0.02$ ] for negative affect and -0.28 [SE $=0.02]$ for positive affect. When work moments were excluded, the estimated effects were 0.17 [SE=0.02] for negative affect and -0.29 [SE=0.02] for positive affect.) Finally, the results could be explained by differences in coping. Lukoff and colleagues (17) put forward the hypothesis that cognitive impairments play an intermediate role between environmental stress and genetic vulnerability, possibly by impairing the coping skills of a patient. The present results do not agree with that hypothesis, at least not as far as coping with events in the flow of daily life is concerned. Patients who are impaired neuropsychologically may display poorer cognitive coping strategies, but poorer coping strategies per se may not lead to increased emotional reaction and therefore greater sensitivity to stress. The advantage of the experience sampling method is that it confers ecological validity to measures of environmental stress.

\section{Clinical Implications}

Although our results are a long way from offering direct therapeutical insights, there are, if sensitivity to stress 
truly is a distinct area of vulnerability, some potentially important clinical implications, as the results suggest that specific therapies may be more useful for specific patients. For example, some patients may benefit more from cognitive remediation therapies, while others would be helped more by focusing on coping techniques in dealing with the stresses of daily life. In other words, it may be useful to tailor treatments according to the dominant underlying mechanism of vulnerability.

\section{Methodological Issues}

The present results should be viewed in light of several methodological issues. First, the results are based on subjective reports. Although subjective reports are considered less reliable (e.g., do all subjects interpret or answer the questions identically?), they can be valid, whereas the validity of objective approaches should not be taken for granted (42). Second, sensitivity to stress has been defined in terms of emotional reaction to subjective stress. The cross-sectional analyses of the data, however, make it impossible to establish a causal relationship. Therefore, the reverse might be true. A worse mood might influence the subjective appraisal of the environment. Third, because of the complexity of the experience sampling method, eight patients were unable to comply adequately with the research protocol and were later excluded from the analysis. The mean levels of activity- and event-related stress, negative and positive affect, positive and negative symptoms, and neuropsychological test scores did not differ, however, between the excluded and included subjects, which suggests that the included subjects were representative of all patients who entered the study.

Received Feb. 16, 2001; revision received May 30, 2001; accepted Aug. 13, 2001. From the Department of Psychiatry and Neuropsychology, European Graduate School of Neuroscience, Maastricht University; and the Division of Psychological Medicine, Institute of Psychiatry, London. Address reprint requests to Dr. van Os, Department of Psychiatry and Neuropsychology (PAR45), Maastricht University, P.O. Box 616, 6200 MD Maastricht, the Netherlands; j.vanos@sp.unimaas.nl (e-mail).

Supported by the Dutch Prevention Fund and the Dutch Brain Society.

The authors thank Truda Driesen, Frieda Van Goethem, and Simonne Delnooz for assistance with the data collection.

\section{References}

1. Cosway R, Byrne M, Clafferty R, Hodges A, Grant E, Abukmeil SS, Lawrie SM, Miller P, Johnstone EC: Neuropsychological change in young people at high risk for schizophrenia: results from the first two neuropsychological assessments of the Edinburgh High Risk Study. Psychol Med 2000; 30:1111-1121

2. Harvey PD, Keefe RSE, Mitroupolou V, DuPre R, Roitman SL, Mohs RC, Siever LJ: Information-processing markers of vulnerability to schizophrenia: performance of patients with schizotypal and nonschizotypal personality disorders. Psychiatry Res 1996; 60:49-56

3. Kraepelin E: Dementia Praecox and Paraphrenia (1919). Translated by Barclay RM; edited by Robertson GM. New York, Robert E Krieger, 1971
4. Weickert TW, Goldberg TE, Gold JM, Bigelow LB, Egan MF, Weinberger DR: Cognitive impairments in patients with schizophrenia displaying preserved and compromised intellect. Arch Gen Psychiatry 2000; 57:907-913

5. Green MF: Schizophrenia From a Neurocognitive Perspective: Probing the Impenetrable Darkness. Boston, Allyn \& Bacon, 1998

6. Andreasen NC, Paradiso S, O'Leary DS: "Cognitive dysmetria" as an integrative theory of schizophrenia: a dysfunction in cortical-subcortical-cerebellar circuitry? Schizophr Bull 1998; 24: 203-218

7. Andreasen NC, Nopoulos P, O'Leary DS, Miller DD, Wassink T, Flaum M: Defining the phenotype of schizophrenia: cognitive dysmetria and its neural mechanisms. Biol Psychiatry 1999; 46:908-920

8. Liddle PF: The symptoms of chronic schizophrenia: a re-examination of the positive-negative dichotomy. Br J Psychiatry 1987; 151:145-151

9. van Os J, Fahy TA, Jones P, Harvey I, Sham P, Lewis S, Bebbington P, Toone B, Williams M, Murray R: Psychopathological syndromes in the functional psychoses: associations with course and outcome. Psychol Med 1996; 26:161-176

10. Green MF: What are the functional consequences of neurocognitive deficits in schizophrenia? Am J Psychiatry 1996; 153: 321-330

11. Harvey PD, Howanitz E, Parrella M, White L, Davidson M, Mohs RC, Hoblyn J, Davis KL: Symptoms, cognitive functioning, and adaptive skills in geriatric patients with lifelong schizophrenia: a comparison across treatment sites. Am J Psychiatry 1998; 155:1080-1086

12. Bebbington P, Wilkins S, Jones P, Foerster A, Murray R, Toone B, Lewis S: Life events and psychosis: initial results from the Camberwell Collaborative Psychosis Study. Br J Psychiatry 1993; 162:72-79

13. Norman RMG, Malla AK: Stressful life events and schizophrenia, I: a review of the research. Br J Psychiatry 1993; 162:161166

14. Malla AK, Cortese L, Shaw TS, Ginsberg B: Life events and relapse in schizophrenia. Soc Psychiatry Psychiatr Epidemiol 1990; 25:221-224

15. Myin-Germeys I, van Os J, Schwartz JE, Stone AA, Delespaul PA: Emotional reactivity to daily life stress in psychosis. Arch Gen Psychiatry 2001; 58:1137-1144

16. Butzlaff RL, Hooley JM: Expressed emotion and psychiatric relapse: a meta-analysis. Arch Gen Psychiatry 1998; 55:547-552

17. Lukoff D, Snyder K, Ventura J, Nuechterlein KH: Life events, familial stress, and coping in the developmental course of schizophrenia. Schizophr Bull 1984; 10:258-292

18. Robins E, Guze SB: Establishment of diagnostic validity in psychiatric illness: its application to schizophrenia. Am J Psychiatry 1970; 126:983-987

19. Ventura J, Green MF, Shaner A, Liberman RP: Training and quality assurance with the Brief Psychiatric Rating Scale: "the drift busters." Int J Methods Psychiatr Res 1993; 3:221-244

20. Kay SR, Fiszbein A, Opler LA: The Positive and Negative Syndrome Scale (PANSS) for schizophrenia. Schizophr Bull 1987; 13:261-276

21. McGuffin P, Farmer A, Harvey I: A polydiagnostic application of operational criteria in psychotic illness: development and reliability of the OPCRIT system. Arch Gen Psychiatry 1991; 48: 764-770

22. Brand $\mathrm{N}$, Jolles J: Learning and retrieval rate of words presented auditorily and visually. J Gen Psychol 1985; 112:201210

23. Lezak MD: Neuropsychological Assessment. New York, Oxford University Press, 1995 
24. Wechsler D: Wechsler Adult Intelligence Scale-Revised Manual. New York, Psychological Corp, 1981

25. Stroop JR: Studies of interference in serial verbal reactions. J Exp Psychol 1935; 18:643-662

26. Houx P, Vreeling F, Jolles J: Age-associated cognitive decline is related to biological life-events, in Alzheimer's Disease: Basic Mechanisms, Diagnosis and Therapeutic Strategies. Edited by Iqbal K, McLachlan D, Winblad B, Wisniewski H. Chichester, UK, John Wiley \& Sons, 1991, pp 353-359

27. Reitan RM: Validity of the Trail Making Test as an indicator of organic brain damage. Percept Mot Skills 1958; 8:271-276

28. Delespaul PAEG: Assessing Schizophrenia in Daily Life. Maastricht, the Netherlands, Maastricht University Press, 1995

29. deVries M (ed): The Experience of Psychopathology: Investigating Mental Disorders in Their Natural Settings. Cambridge, UK, Cambridge University Press, 1992

30. Myin-Germeys I, Delespaul PA, deVries MW: Schizophrenia patients are more emotionally active than is assumed based on their behavior. Schizophr Bull 2000; 26:847-854

31. Myin-Germeys I, Nicolson NA, Delespaul PAEG: The context of delusional experiences in the daily life of schizophrenia patients. Psychol Med 2001; 31:489-498

32. Goldstein H: Multilevel Models in Educational and Social Research. London, Charles Griffin, 1987

33. Schwartz JE, Stone AA: Strategies for analyzing ecological momentary assessment data. Health Psychol 1998; 17:6-16

34. Faraone SV, Seidman LJ, Kremen WS, Toomey R, Pepple JR, Tsuang MT: Neuropsychologic functioning among the nonpsy- chotic relatives of schizophrenic patients: the effect of genetic loading. Biol Psychiatry 2000; 48:120-126

35. Krabbendam L, Marcelis M, Delespaul P, Jolles J, van Os J: Single or multiple familial cognitive risk factors in schizophrenia? Am J Med Genet 2001; 105:183-188

36. Carpenter WT Jr, Heinrichs DW, Wagman AMI: Deficit and nondeficit forms of schizophrenia: the concept. Am J Psychiatry 1988; 145:578-583

37. Crow TJ: Molecular pathology of schizophrenia: more than one disease process? Br Med J 1980; 280:66-68

38. Murray RM, O'Callaghan E, Castle DJ, Lewis SW: A neurodevelopmental approach to the classification of schizophrenia. Schizophr Bull 1992; 18:319-332

39. van Os J, Jones P, Sham P, Bebbington P, Murray RM: Risk factors for onset and persistence of psychosis. Soc Psychiatry Psychiatr Epidemiol 1998; 33:596-605

40. Hawkins KA, Hoffman RE, Quinlan DM, Rakfeldt J, Docherty NM, Sledge WH: Cognition, negative symptoms, and diagnosis: a comparison of schizophrenic, bipolar, and control samples. J Neuropsychiatry Clin Neurosci 1997; 9:81-89

41. Kring AM, Neale JM: Do schizophrenic patients show a disjunctive relationship among expressive, experiential, and psychophysiological components of emotion? J Abnorm Psychol 1996; 105:249-257

42. Strauss JS: The person with schizophrenia as a person, II: approaches to the subjective and complex. Br J Psychiatry Suppl 1994; 23:103-107 